\title{
Ultrasound-guided Low Thoracic Erector Spinae Plane Block for Effective Postoperative Analgesia after Lumbar Surgery: Report of Five Cases
}

\author{
Sevim Cesur $^{1}$, Ahmet Murat Yayik ${ }^{1}$, Figen Ozturk ${ }^{1}$, Ali Ahiskalioglu ${ }^{2}$ \\ 1. Anesthesiology, Regional Training Research Hospital, Erzurum, TUR 2. Anesthesiology, Ataturk University School of \\ Medicine, Erzurum, TUR
}

Corresponding author: Ahmet Murat Yayik, m_yayik@hotmail.com

\begin{abstract}
Pain control is an important administration of postoperative management in lumbar spinal surgery, and multimodal analgesia is most likely an important strategy in reducing postoperative spinal surgery. Erector spinae plane (ESP) block is a recently described regional anaesthesia technique that blocks the dorsal and ventral rami of the spinal nerves and the sympathetic nerve fibers. While the ESP block has been shown to provide effective postoperative analgesia after thoracic, breast, and abdominal surgery in case reports and randomised controlled studies, there are only a few case series that report that an ultrasonography (US)guided bilateral ESP block provides effective postoperative analgesia in lumbar surgery. We report five patients undergoing lumbar surgery in which a bilateral lower thoracic ESP block was used as the postoperative analgesia. The bilateral ESP block may be a promising anesthetic method for postoperative analgesia following lumbar surgery. Our aim is testing the safety and efficacy of this technique in various surgical procedures by conducting prospective studies.
\end{abstract}

Categories: Anesthesiology, Pain Management

Keywords: erector spinae plane block, spinal surgery, postoperative analgesia

\section{Introduction}

Interfascial plane block has recently become very popular for postoperative analgesia management for clinicians. Papers on the erector spinae plane (ESP) block, which was introduced by Forero et al. as a novel fascial plane block in 2016, are on the rise in the literature [1]. ESP appears to be a promising regional method for postoperative analgesia management in thoracic and abdominal surgeries in both adult and pediatric patients $[2-4]$.

Received 11/05/2018

Review began 11/08/2018 Review ended 11/14/2018 Published 11/16/2018

๑) Copyright 2018

Cesur et al. This is an open access article distributed under the terms of the Creative Commons Attribution License CC-BY 3.0., which permits unrestricted use, distribution, and reproduction in any medium, provided the original author and source are credited.
Despite the wide spectrum of indications of the technique, there are a few publications in the literature for the use of this technique in lumbar spinal surgery [5].

Our aim in these case series was to investigate bilateral lower thoracic ESP block for providing successful postoperative pain management following lumbar surgery.

\section{Case Presentation}

All of the data used in this manuscript were collected after the approval and written consent of all the patients.

All patients were positioned in a prone position for preoperative ESP block application. The skin was prepared with chlorhexidine $2 \%$ in a sterile fashion. The ESP block was performed using an Esaote MyLab ${ }^{\mathrm{TM}}$ 30 US machine (Esaote SpA, Florence, Italy) with a large bandwidth and multifrequency linear probe (10-18 $\mathrm{MHz}$ ) of 22G-80 mm containing an insulated facet type needle (Braun Sonoplex, Melsungen, Germany). The ultrasonography (US) probe was placed on the spinal column at the level of T12 laterally by means of the guidance of the twelfth rib (Figure 1). The erector spinae muscle and the transverse process were seen. After negative aspiration, the needle position was confirmed by the administration of a normal saline solution. A $20 \mathrm{ml}$ local anesthetic solution containing bupivacaine $0.25 \%$ and lidocaine $1 \%$ was injected deep into the erector spinae muscle in the course of the direction from cranial to caudal. 


\section{Cureus}

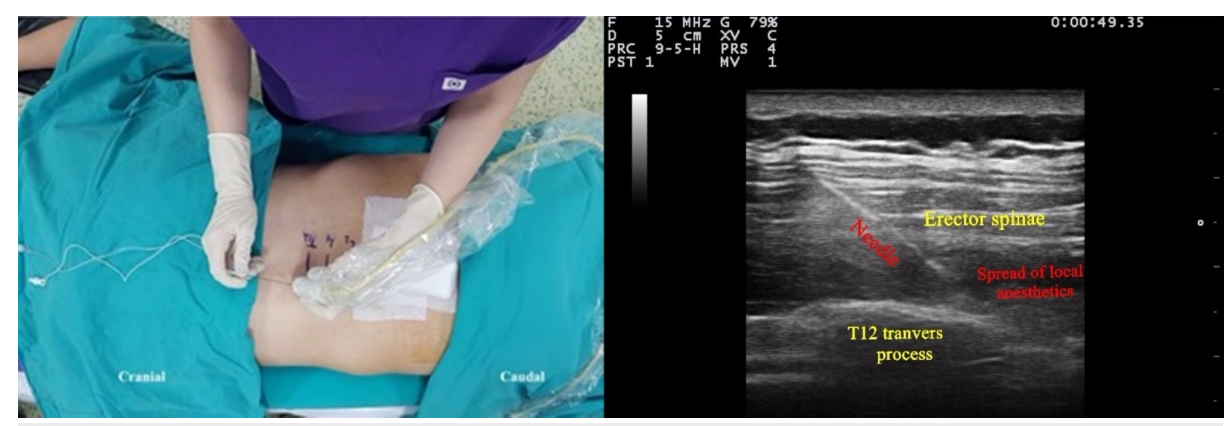

\section{FIGURE 1: Patient position and sonographic anatomy of ESP}

ESP: erector spinae plane

Each patient was taken to the operating room after the dermatomal spread.

All patients received $400 \mathrm{mg}$ intravenous (IV) ibuprofen in a $100 \mathrm{ml}$ saline solution 30 minutes before surgery. For all the patients, a standard monitorization method was applied. Anaesthesia was induced with propofol $2 \mathrm{mg} / \mathrm{kg}$, fentanyl $2 \mathrm{mcg} / \mathrm{kg}$, and rocuronium $0.6 \mathrm{mg} / \mathrm{kg}$. Each patient was then intubated with a spiral cuffed endotracheal tube (ETT) (women with 7.5 no ETT; men with 8.0 no ETT). Anesthesia maintenance was achieved with a desflurane $6 \%$ combination with nitrous oxide in oxygen at a proportion of 2:1 in 3 liters (L) of fresh gas flow. The patients were ventilated to maintain an end-tidal carbon dioxide level of 35 - $40 \mathrm{mmHg}$. Radial artery catheterization was performed in the non-dominant hand of all patients using a $20 \mathrm{G}$ catheter for invasive blood pressure monitorization and arterial blood gas (ABG) analysis after induction. The hemodynamics of each patient were closely followed during surgery with no complications. At the end of the surgery, tramadol-based patient-controlled analgesia (PCA) was administered before extubation. The patients were then extubated and taken to the postoperative recovery unit. The Numeric Pain Rating Scale (NPRS) for pain was recorded every hour during the 24-hour postoperative follow-up period. Please refer to Table 1 below for a summary of clinical details for all five patients. 


\section{Cureus}

\begin{tabular}{|c|c|c|c|c|c|}
\hline & Case 1 & Case 2 & Case 3 & Case 4 & Case 5 \\
\hline $\begin{array}{l}\text { Demographic/ } \\
\text { clinical details }\end{array}$ & $\begin{array}{l}52 \text {-year-old } \\
\text { male, } 80 \mathrm{~kg} \text {, } \\
172 \mathrm{~cm}, \text { ASA } \\
1\end{array}$ & $\begin{array}{l}\text { 60-year-old female, } 76 \\
\mathrm{~kg}, 155 \mathrm{~cm} \text {, diabetes } \\
\text { mellitus, ASA } 2\end{array}$ & $\begin{array}{l}\text { 48-year-old male, } 88 \mathrm{~kg}, 176 \\
\mathrm{~cm} \text {, hypertension and } \\
\text { diabetes mellitus, ASA } 2\end{array}$ & $\begin{array}{l}\text { 34-year-old } \\
\text { female, } 67 \mathrm{~kg} \text {, } \\
156 \mathrm{~cm}, \text { ASA } 1\end{array}$ & $\begin{array}{l}\text { 57-year-old male, } 84 \\
\mathrm{~kg}, 180 \mathrm{~cm} \text {, significant } \\
\text { smoking history }\end{array}$ \\
\hline Surgery type & $\begin{array}{l}\text { Lumbar disc } \\
\text { herniation } \\
\text { (L3-4) }\end{array}$ & $\begin{array}{l}\text { Lumbar } \\
\text { instrumentation (L2-4) }\end{array}$ & Lumbar disc herniation (L2) & $\begin{array}{l}\text { Lumbar disc } \\
\text { herniation (L4) }\end{array}$ & $\begin{array}{l}\text { Lumbar } \\
\text { instrumentation (L3-5) }\end{array}$ \\
\hline $\begin{array}{l}\text { Duration of } \\
\text { surgery }\end{array}$ & 2 hours & 4 hours & 2 hours & 1 hour & 3 hours \\
\hline $\begin{array}{l}\text { NPRS postop } 4 \\
\text { hours }\end{array}$ & 0 & 3 & 2 & 0 & 3 \\
\hline $\begin{array}{l}\text { NPRS postop } 8 \\
\text { hours }\end{array}$ & 2 & 4 & 2 & 0 & 3 \\
\hline $\begin{array}{l}\text { NPRS postop } 12 \\
\text { hours }\end{array}$ & 2 & 4 & 2 & 2 & 4 \\
\hline $\begin{array}{l}\text { NPRS postop } \\
24 \text { hours }\end{array}$ & 4 & 5 & 3 & 2 & 4 \\
\hline $\begin{array}{l}\text { Postoperative } \\
\text { total tramadol } \\
\text { consumption use }\end{array}$ & $60 \mathrm{mg}$ & $150 \mathrm{mg}$ & $45 \mathrm{mg}$ & $30 \mathrm{mg}$ & $100 \mathrm{mg}$ \\
\hline
\end{tabular}

\section{TABLE 1: Summary of the Five Patients in This Case Series}

NPRS: Numeric Pain Rating Scale ranges from 0 (no pain) to 10 (worst pain imaginable); ASA 1 and 2: American Society of Anesthesiologists Scores

\section{Discussion}

Pain control is an important direction of postoperative management in lumbar spinal surgery. Inadequate pain control increases cardiac and respiratory complications, as well as delays mobilization, increasing the length of hospital stay and the risk of chronic pain syndrome [6]. For all these reasons, multimodal analgesia is most likely an important strategy in reducing postoperative pain following spinal surgery [7]. Opioids are known to play a role in moderate-to-severe pain management, while NSAIDs are effective in pain management where inflammation is the cause. However, the side effects of opioids, such as respiratory depression, nausea, vomiting, and pruritus, should also be considered. Zhang et al. reported that the use of NSAIDs in lumbar spinal surgery was effective in postoperative pain management in a meta-analysis, and the surgery type and NSAIDs dosage have an important role in the analgesic effect. Systemic methods, as well as regional methods, are an important step in multimodal analgesia. Neuraxial blockade includes epidural and spinal blocks managed via a single bolus, continuous infusion, or patient-controlled delivery systems. Although neuraxial blockade reduces opioid consumption and side effects, these blocks may cause hemodynamic instability and motor block [8]. Recently, interfascial plan blocks have started to be involved in postoperative pain management after lumbar surgery [9-10]. Interfascial plane blocks reduce opioid consumption without motor blocks, such as neuraxial blocks, providing adequate long-lasting postoperative analgesia [11].

The newest interfascial plane block, the ESP block, is a block made by injecting local anesthesia between the deep fascia of the erector spinae muscle and the transverse process and targeting the dorsal and ventral rami of the spinal nerves. Although studies have not completely defined the mechanism of the ESP block, the analgesic efficacy of the ESP block is thought to be due to local anesthetics spreading to the paravertebral space $[1,12]$.

The ESP block has provoked the curiosity and interest of clinicians as the paravertebral distribution associated with the block has been established and the method is relatively easier and safer to apply compared to the paravertebral block. Thus, the publication of data on the successful management of postoperative analgesia by the application of the ESP technique at the level of T5 after the thoracic and breast surgeries has been followed currently by reports on the use of that method at various levels for a range of indications from acute herpes zoster treatment at low thoracic levels to abdominal and hip surgeries [13-15]. 
In this case series, we observed that the ESB achieved effective analgesia and reduced opioid consumption in the single or multilevel lumbar spine surgeries of five patients during the postoperative first 24 hours.

\section{Conclusions}

In conclusion, on the basis of this small case series, it appears that bilateral US-guided ESP block is a safe and effective technique for postoperative pain management after lumbar spine surgery.

We recommend testing of the safety and efficacy of this technique in various surgical procedures by conducting prospective studies.

\section{Additional Information \\ Disclosures}

Human subjects: Consent was obtained by all participants in this study. Erzurum Training and Research Hospital Ethical Board issued approval NA. Written informed consent was obtained from all patients in this report. Ethics board approval for case report is not required by our institute. Conflicts of interest: In compliance with the ICMJE uniform disclosure form, all authors declare the following: Payment/services info: All authors have declared that no financial support was received from any organization for the submitted work. Financial relationships: All authors have declared that they have no financial relationships at present or within the previous three years with any organizations that might have an interest in the submitted work. Other relationships: All authors have declared that there are no other relationships or activities that could appear to have influenced the submitted work.

\section{References}

1. Forero M, Adhikary SD, Lopez H, Tsui C, Chin KJ: The erector spinae plane block: a novel analgesic technique in thoracic neuropathic pain. Reg Anesth Pain Med. 2016, 41:621-27. 10.1097/AAP.0000000000000451

2. Ueshima $\mathrm{H}$, Otake $\mathrm{H}$ : Clinical experiences of ultrasound-guided erector spinae plane block for thoracic vertebra surgery. J Clin Anesth. 2017, 38:137.

3. Chin KJ, Malhas L, Perlas A: The erector spinae plane block provides visceral abdominal analgesia in bariatric surgery. A report of 3 cases. Reg Anesth Pain Med. 2017, 42:372-76. 10.1097/AAP.0000000000000581

4. Aksu C, Gürkan Y: Ultrasound guided erector spinae block for postoperative analgesia in pediatric nephrectomy surgeries. J Clin Anesth. 2018, 45:35-36.

5. Melvin JP, Schrot RJ, Chu GM, Chin KJ: Low thoracic erector spinae plane block for perioperative analgesia in lumbosacral spine surgery: a case series. Can J Anaesth. 2018, 65:1057-65. 10.1007/s12630-018-1145-8

6. Thepsoparn M, Sereeyotin J, Pannangpetch P: Effects of combined lower thoracic epidural/general anesthesia on pain control in patients undergoing elective lumbar spine surgery: a randomized controlled trial. Spine (Phila Pa 1976). 2018, 43:1381-85.

7. Nielsen RV: Adjuvant analgesics for spine surgery. Dan Med J. 2018, 65:B5468

8. Sinatra RS, Torres J, Bustos AM: Pain management after major orthopaedic surgery: current strategies and new concepts. J Am Acad Orthop Surg. 2002, 10:117-29.

9. Ezhevskaya AA, Mlyavykh SG, Anderson DG: Effects of continuous epidural anesthesia and postoperative epidural analgesia on pain management and stress response in patients undergoing major spinal surgery. Spine (Phila Pa 1976). 2013, 38:1324-30. 10.1097/BRS.0b013e318290ff26

10. Ahiskalioglu A, Yayik AM, Alici HA: Ultrasound-guided lateral thoracolumbar interfascial plane (TLIP) block: description of new modified technique. J Clin Anesth. 2017, 40:62.

11. Chin KJ, McDonnell JG, Carvalho B, Sharkey A, Pawa A, Gadsden J: Essentials our current understanding: abdominal wall blocks. Reg Anesth Pain Med. 2017, 42:133-83. 10.1097/AAP.0000000000000545

12. Vidal E, Giménez H, Forero M, Fajardo M: Erector spinae plane block: a cadaver study to determine its mechanism of action. Rev Esp Anestesiol Reanim. 2018, 65:514-19. 10.1016/j.redar.2018.07.004

13. Bonvicini D, Tagliapietra L, Giacomazzi A, Pizzirani E: Bilateral ultrasound-guided erector spinae plane blocks in breast cancer and reconstruction surgery. J Clin Anesth. 2018, 44:3-4.

14. Ahiskalioglu A, Alici HA, Ari MA: Ultrasound guided low thoracic spinae plane block for management of acute herpes zoster. J Clin Anesth. 2018, 45:60-61.

15. Tulgar S, Senturk O: Ultrasound guided erector spinae plane block at L-4 transverse process level provides effective postoperative analgesia for total hip arthroplasty. J Clin Anesth. 2018, 44:68. 